\title{
Utilizing the Azaazulene Scaffolds in the Design of New Organic Superbases
}

\author{
Danijela Baríc*(i) \\ Department of Physical Chemistry, Ruder Bošković Institute, Bijenička 54, 10000 Zagreb, Croatia \\ Supporting Information
}

ABSTRACT: New neutral organic superbases with 1-azaazulene(s) as a molecular backbone are computationally designed, employing two basic substituents: dimethylaminocyclopropen-imines (CPI) and dimethylaminocyclopropeniminophosphazenes (CPI-P). Their proton affinities, gas basicities, and $\mathrm{pK}_{\mathrm{a}}$ values in acetonitrile are obtained using density functional theory. Azaazulenes substituted with CPI have a computed PA in the gas phase ranging between 272.9 and $306.8 \mathrm{kcal} \mathrm{mol}^{-1}$, with $\mathrm{p} K_{\mathrm{a}}$ values in acetonitrile between 28.8 and 36 units. The substitution with the CPI-P group resulted in even stronger superbases, with a PA from 296.5 to 335.2 $\mathrm{kcal} \mathrm{mol}^{-1}$ and corresponding $\mathrm{p} K_{\mathrm{a}}$ values from 33.9 to 50 units. This exceptionally strong thermodynamic basicity is accompanied by very high kinetic basicity as well; contrary to typical proton sponges, the release of a proton from the conjugate superbase does not demand high activation energy. Because synthetic routes for both substituents and azaazulenes are

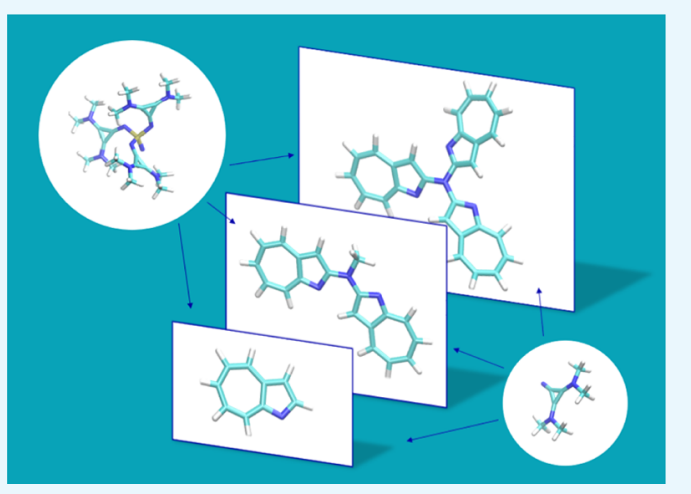
already known, newly designed superbases represent suitable targets for synthesis and application.

\section{INTRODUCTION}

Neutral organic bases are compounds extensively used as catalysts in synthetic organic chemistry, due to their ability to initiate a reaction by spontaneous deprotonation of reagents. ${ }^{1}$ The important advantages of neutral organic bases over their ionic inorganic counterparts are much better solubility in organic solvents and milder reaction conditions. Organic compounds that are more basic than the proton sponge 1,8bis(dimethylamino)naphthalene (DMAN), with a proton affinity (PA) of $245.3 \mathrm{kcal} \mathrm{mol}^{-1}$ and a gas basicity (GB) of $239 \mathrm{kcal} \mathrm{mol}^{-1}$, are called superbases. ${ }^{2}$ From the structural point of view, the general definition of superbases characterizes them as bases composed of multiple basic units. ${ }^{3}$ A great majority of neutral organic superbases known so far are nitrogen bases, as pointed out in a recent comprehensive review article by Raczyńska et al. ${ }^{4}$ where the gas phase basicity of various nitrogen bases including organic compounds, but also some biomolecules, is analyzed, based mostly on the experimental data. However, there are some examples of prepared superbases where carbon or phosphorus acts as a basicity center ${ }^{5-7}$ and recently very strong silylene superbases have been designed computationally. ${ }^{8}$ A theoretical design of organic superbases along with computational elucidation of effects responsible for their superbasic properties represent a vital stage for synthesis and a range of application of these compounds, as emphasized in an earlier review article by Maksic et al. ${ }^{9}$ Although the great number of neutral organic superbases is already available, most of them are still not as basic as inorganic bases such as lithium diisopropylamide whose $\mathrm{p} K_{\mathrm{a}}$ in tetrahydrofuran is $35.7 .^{10}$ For comparison, $\mathrm{p} K_{\mathrm{a}}$ of the strongest commercially available superbase, phosphazene $t \mathrm{Bu}-\mathrm{P} 4$, in tetrahydrofuran is 33.9. ${ }^{7 \mathrm{~b}}$ Moreover, theoretical investigation of fundamental thermochemistry of neutral organic superbases and exploration of basicity limits can offer insights needed for the design of new reagents and new chemical reactions in synthetic organic chemistry.

Depending on basic functional groups present in a molecule, neutral organic (super)bases may be grouped into several classes: amines, ${ }^{1,4}$ amidines, ${ }^{11}$ guanidines, ${ }^{12}$ phosphazenes, ${ }^{13}$ pyridines, ${ }^{14}$ phosphines, $^{7 \mathrm{~b}, 15}$ and cyclopropenimines ${ }^{16}$ (Scheme 1). A combination of these functionalities enables obtaining even more basic compounds, such as cyclopropeniminoguanidines, ${ }^{17}$ guanidinophosphazenes, ${ }^{18}$ and cyclopropeniminophosphazenes, ${ }^{17 \mathrm{~b}, 19}$ also shown in Scheme 1 . Superbase DMAN, synthesized by Alder fifty years ago, ${ }^{20}$ represents a special example of an amine with two dimethylamino substituents at positions 1 and 8 of naphthalene. Because of the repulsion of electron pairs on nitrogen atoms, the neutral form of the molecule is destabilized; however, in a protonated form this repulsive interaction diminishes, which has a positive effect on basicity. Protonation also induces the formation of an intramolecular $\mathrm{H}$ bond which additionally stabilizes the protonated form, thus leading to further increase of basicity. On the other side, the proximity of amino groups induces a proton shielding, ${ }^{21,22}$ which means that once the proton is captivated into the

Received: July 7, 2019

Accepted: August 20, 2019

Published: September 4, 2019 


\section{Scheme 1. Main Classes of Neutral Organic (Super)bases}

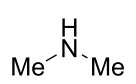

Dimethylamine<smiles>CC(=N)N(C)C</smiles>

$N, N$-Dimethylacetamidine<smiles>CN(C)c1ccncc1</smiles>

4-Dimethylaminopyridine

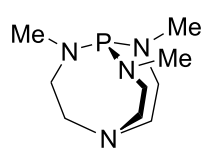

Phosphine

(Verkade's superbase)

1,1,3,3-Tetramethylguanidine

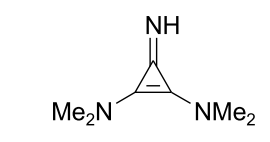

1,2-(N,N-dimethylamino)cyclopropenimine (CPI)<smiles>CN(C)c1cccc2cccc(N(C)C)c12</smiles>

1,8-bis(dimethylamino)naphthalene (DMAN)

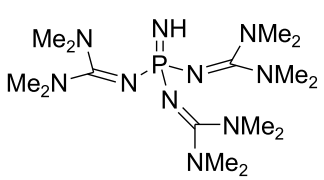

Guanidinophosphazene<smiles>CN(C)c1c(N)c1=NC(=N)N=c1c(N)c1N(C)C</smiles>

Cyclopropeniminoguanidine

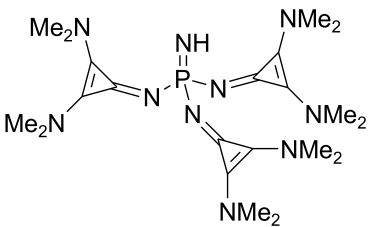

Cyclopropeniminophosphazene (CPI-P) molecule, it cannot be easily released. This behavior, which is typical of bases similar to DMAN where the aromatic backbone enables proximity of basic substituents, is the reason why this type of superbases is called proton sponges. Pozharskii et al. extensively investigated different naphthalene-based proton sponges and its analogs, including those with expanded $\mathrm{N}$-alkyl groups and $\mathrm{N}$-substituents other than alkyl groups, ${ }^{23 a}$ chiral proton sponges, ${ }^{23 b}$ proton sponges with different ortho-substituents (e.g., based on tertiary alcohols) ) $^{23 c}$ that interact with dimethylamino groups. It is interesting that some naturally occurring compounds, like mycosporine-like amino acid named porphyra-334 ${ }^{24 \mathrm{a}}$ and aplicyanines, ${ }^{24 \mathrm{~b}}$ also act as proton sponges. The kinetic inertness of typical proton sponges in some cases limits their use as basic catalysts in organic synthesis. $^{22 c}$

The computational investigation of the basicity of superbases that contain substituents based on 1,2-(N,N-dimethylamino)-cyclopropenimine (in further text CPI) predicted that they should be more basic than guanidines ${ }^{1,2,9}$ and possibly even phosphazenes. ${ }^{13}$ In 2010 a convenient two-step synthesis of cyclopropenimines was reported by Alcarazo and coworkers, ${ }^{25}$ which encouraged further research and development of superbasic compounds with a cyclopropenimine motif. The synthesis of the enantioselective Brønsted base organocatalyst 2,3-bis(di-isopropylamino)cyclopropenimine ${ }^{16 \mathrm{c}}$ confirmed the theoretical predictions of its solution basicity with a $\mathrm{p} K_{\mathrm{a}}$ measured in acetonitrile of 26.90, which is indeed more basic than guanidines ( $\mathrm{p} K_{\mathrm{a}}$ of analogous guanidine 23.56). Subsequently, proton sponges with CPI as pincer ligands were prepared too. ${ }^{26}$ Superbases containing cyclopropenimino functionality owe their high basicity to the aromatic stabilization of the cyclopropenium cation that is formed upon protonation of the system, as shown in Scheme 2. ${ }^{27}$
Scheme 2. Formation of a Cyclopropenium Cation<smiles>CN=C1C(NC)[C@@H](C)C1N(C)C</smiles>

The combination of CPI and phosphazene moieties results in "higher-order cyclopropenimino superbases", ${ }^{17 b}$ cyclopropeniminophosphazenes (CPI-P), compounds that are more basic than each of its components taken separately. One such superbase, consisting of phosphazene as a core and three diisopropylaminocyclopropenimino substituents, was synthesized, ${ }^{17 \mathrm{~b}}$ and its $\mathrm{p} K_{\mathrm{a}}$ in acetonitrile was found to be 42.1. The CPI-P functionality was also utilized in the computational design of very strong proton sponges, with a calculated gas phase PA above $323 \mathrm{kcal} \mathrm{mol}^{-1}$ and a $\mathrm{pK}$ in acetonitrile of 48 units, ${ }^{19}$ which represents the most basic proton sponge designed so far. However, similar to other proton sponges, this superbase is kinetically inert; the calculated activation energy needed for the release of a proton from the conjugate acid is very high. ${ }^{19}$

We wondered what alternative aromatic scaffold could be used in combination with a CPI and CPI-P motif that would result in a strong superbasicity and, at the same time, would not suffer from kinetic inertness that occurs in proton sponges. Azaazulenes are nitrogen-containing analogs of azulene, an aromatic molecule which is an isomer of naphthalene. Among azaazulenes, 1-azaazulene is known as a very stable and easily synthesized compound, with several well-established synthetic paths for its preparation and preparation of its derivatives. ${ }^{28-31}$ The experimental data on the basicity of 1 -azaazulene are not available, but the calculated GB of this compound is $231.9 \mathrm{kcal}$ 
$\mathrm{mol}^{-1}\left(\mathrm{PA}=239.5 \mathrm{kcal} \mathrm{mol}^{-1}\right)$. So far, azaazulenes have never been used in the design and preparation of organic superbases.

In this work, we present a novel, computationally designed neutral organic superbases, obtained by utilizing two types of substituents dimethylaminocyclopropenimines, CPI, and dimethylaminocyclopropeniminophosphazenes, CPI-P which are combined with 1-azaazulene as a core unit(s). Further, we have investigated their kinetic basicity by calculation of free energy barriers for a proton exchange reaction between the neutral and protonated form of the same superbase.

\section{COMPUTATIONAL METHODS}

All calculations were obtained using the Gaussian09 program package. $^{32}$ The geometries of all structures were optimized at the B3LYP/6-31G(d) level of theory, and the vibrational analysis was performed to verify the minima or transition states on the potential energy surface for all structures.

Calculations of PAs in the gas phase and GBs were carried out at the B3LYP/6-311+G(3df,2p)//B3LYP/6-31G(d) level of theory. The PA of the molecule $\mathrm{B}$ is expressed as a negative change of enthalpy at $298 \mathrm{~K}$ for the reaction of protonation

$$
\mathrm{B}+\mathrm{H}^{+} \rightarrow \mathrm{BH}^{+}
$$

Thus, the PA is calculated according to the equation

$$
\mathrm{PA}=-\Delta_{\mathrm{r}} H^{298}=H^{298}(\mathrm{~B})+(5 / 2) R T-H^{298}\left(\mathrm{BH}^{+}\right)
$$

Terms $H^{298}(\mathrm{~B})$ and $H^{298}\left(\mathrm{BH}^{+}\right)$are the enthalpies at $298 \mathrm{~K}$ of the neutral (B) and protonated $\left(\mathrm{BH}^{+}\right)$base, obtained as a sum of total energy and thermal correction to the enthalpy calculated at the level of theory mentioned above, whilst $(5 / 2)$ $R T$ corresponds to the enthalpy of the proton.

GB represents a negative change of Gibbs energy for reaction 1 , that is, it is a difference between the sum of the calculated Gibbs energy of the neutral base and the Gibbs energy of the proton and the calculated Gibbs energy of the protonated base

$$
\mathrm{GB}=-\Delta G^{298}=G^{298}(\mathrm{~B})+G^{298}\left(\mathrm{H}^{+}\right)-G^{298}\left(\mathrm{BH}^{+}\right)
$$

The Gibbs energy of the proton in the gas phase, $G^{298}\left(\mathrm{H}^{+}\right)$, has a value of $-6.29 \mathrm{kcal} \mathrm{mol}^{-1}, 33$ whereas the Gibbs energy of $\mathrm{B}$ and $\mathrm{BH}^{+}$, respectively, is obtained as a sum of the total energy and thermal correction to Gibbs energy calculated at the aforementioned level of theory.

$\mathrm{p} K_{\mathrm{a}}$ values in acetonitrile $(\mathrm{MeCN})$ are estimated using two theoretical approaches. The first one is a procedure developed by Glasovac et al., ${ }^{34}$ which is based on the correlation between experimental $\mathrm{p} K_{\mathrm{a}}$ values and calculated basicities

$$
\mathrm{p} K_{\mathrm{a}}=0.545 \Delta G_{\mathrm{a}, \mathrm{sol}}^{\prime}\left(\mathrm{BH}^{+}\right)-133.5
$$

Term $\Delta G_{\mathrm{a}, \mathrm{sol}}^{\prime}\left(\mathrm{BH}^{+}\right)$represents the negative change of Gibbs energy for the reaction of protonation of a base (eq 1) in acetonitrile. The Gibbs energy $\left(G_{\mathrm{a}, \mathrm{sol}}^{\prime}\right)$ is obtained as a sum of total electronic energy, the thermal correction to Gibbs energy and the energy of solvation. The energies of solvation are calculated using the isodensity polarizable continuum (IPCM) method at the B3LYP/6-311+G(d,p)//B3LYP/6-31G(d) level of theory.

The second approach used in this work for the estimation of $\mathrm{p} K_{\mathrm{a}}$ values is based on a conductor-like polarizable continuum model of solvation, CPCM. ${ }^{35}$ We utilized the thermodynamic cycle presented in Scheme 3, where pyridine with the experimental value of $\mathrm{p} K_{\mathrm{a}}$ of $12.53^{36}$ served as a reference base $B_{\text {ref }}$.

Scheme 3. Thermodynamic Cycle Utilized for the Calculation of $\mathrm{pK}$ a with the CPCM Approach

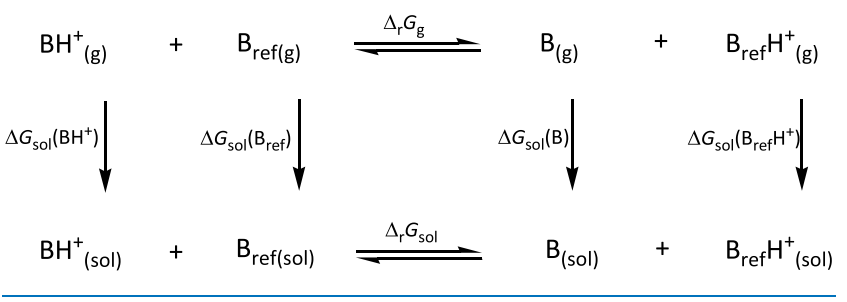

The $\mathrm{p} K_{\mathrm{a}}$ values of the investigated superbases were given as

$$
\mathrm{p} K_{\mathrm{a}}(\mathrm{B})=\Delta_{\mathrm{r}} G_{\mathrm{sol}} / R T \ln 10+\mathrm{p} K_{\mathrm{a}}\left(\mathrm{B}_{\text {ref }}\right)
$$

The overall Gibbs energy reaction change in solution $\Delta_{\mathrm{r}} G_{\mathrm{sol}}$, is calculated as follows

$$
\begin{aligned}
& \Delta_{\mathrm{r}} G_{\mathrm{sol}}=\left(G_{\mathrm{g}}(\mathrm{B})+\Delta G_{\mathrm{sol}}(\mathrm{B})+G_{\mathrm{g}}\left(\mathrm{B}_{\mathrm{ref}} \mathrm{H}^{+}\right)\right. \\
& \left.\quad+\Delta G_{\mathrm{sol}}\left(\mathrm{B}_{\mathrm{ref}} \mathrm{H}^{+}\right)\right)-\left(G_{\mathrm{g}}\left(\mathrm{BH}^{+}\right)+\Delta G_{\mathrm{sol}}\left(\mathrm{BH}^{+}\right)\right. \\
& \left.\quad+G_{\mathrm{g}}\left(\mathrm{B}_{\mathrm{ref}}\right)+\Delta G_{\mathrm{sol}}\left(\mathrm{B}_{\mathrm{ref}}\right)\right)
\end{aligned}
$$

where the Gibbs energies in the gas phase $\left(G_{\mathrm{g}}\right)$ represent a sum of total energy calculated at the B3LYP/6-311+G(3df,2p)//B3LYP/6-31G(d) level of theory and thermal correction for Gibbs energy. The values of $\Delta G_{\text {sol }}$ are calculated using the (CPCM)/B3LYP/6-31G(d)//B3LYP/6-31G(d) model.

\section{RESULTS AND DISCUSSION}

3.1. 1-Azaazulenes with Cyclopropenimino and Cyclopropeniminophosphazeno Substituents. It is expected that the substitution of azaazulenes with strong electron-donating groups such as cyclopropenimino (CPI) and cyclopropeniminophosphazeno (CPI-P), would result in an enhanced basicity of this aromatic compound. Calculations predict that 1-azaazulene with the gas phase PA of $239.5 \mathrm{kcal}$ $\mathrm{mol}^{-1}$, is more basic than pyridine, whose PA is $223.8 \mathrm{kcal}$ $\mathrm{mol}^{-1}$ (computed at the same level of theory). Pyridine is an example of nitrogen-containing aromatic molecule that has been frequently used as a structural motif for design and preparation of many superbases. ${ }^{4,14,37}$ We have investigated herein whether 1-azaazulene could also serve as a core unit in the design of novel superbases.

To investigate the positions of the substituent on the azaazulene ring that are most favorable for basicity enhancement, we calculated the PA and GB for 1-azaazulenes substituted with one CPI group at each of the seven possible positions of the molecule (Figure 1). Because the protonation of CPI-monosubstituted azaazulenes (denoted as $\boldsymbol{n}$-Ac) may occur at the $\mathrm{N}$ atom of azaazulene $\left(\mathrm{N}_{\text {azaazulene }}\right)$ but also at the imino nitrogen of the CPI substituent $\left(\mathrm{N}_{\mathrm{CPI}}\right)$, we compared $\mathrm{GB}$ and PA values for protonation at both sites. It should be mentioned that other potential protonation sites are amino groups of the CPI substituent; however, their PAs are very low in comparison to the nitrogen of the azaazulene ring and the imino group of the CPI substituent.

Table 1 contains the gas phase PAs and GBs for a series of seven monosubstituted cyclopropenimino-1-azaazulenes (schematically presented in Figure 1), calculated for protonation of $\mathrm{N}_{\text {azaazulene }}$ and $\mathrm{N}_{\mathrm{CPI}}$, respectively. 


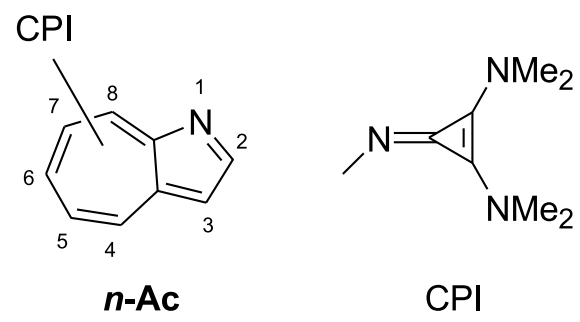

Figure 1. Monosubstituted cyclopropenimino-1-azaazulenes, $n$-Ac, where $n$ denotes the position of the substituent on the 1-azaazulene rings $(n=2,3,4,5,6,7$, and 8$)$.

Table 1. Gas Phase PAs and GBs of Monocyclopropenimino-Azaazulenes (in $\mathrm{kcal} \mathrm{mol}^{-1}$ ), for Protonation at Azaazulene Nitrogen $\left(\mathrm{N}_{\text {azaazulene }}\right)$, and at the Imino Group of the CPI Substituent $\left(\mathrm{N}_{\mathrm{CPI}}\right)$

\begin{tabular}{ccccc} 
molecule & PA $\left(\mathrm{N}_{\text {azaazulene }}\right)$ & $\mathrm{GB}\left(\mathrm{N}_{\text {azaazulene }}\right)$ & PA $\left(\mathrm{N}_{\mathrm{CPI}}\right)$ & $\mathrm{GB}\left(\mathrm{N}_{\mathrm{CPI}}\right)$ \\
2-Ac & 257.4 & 250.5 & 256.9 & 250.0 \\
3-Ac & 256.3 & 249.0 & 257.2 & 251.3 \\
4-Ac & 267.0 & 260.0 & 249.6 & 242.5 \\
5-Ac & 262.4 & 255.5 & 251.6 & 245.5 \\
6-Ac & 266.8 & 260.0 & 249.6 & 243.0 \\
7-Ac & 264.0 & 257.3 & 252.8 & 246.7 \\
8-Ac & 272.9 & 265.3 & 262.1 & 254.5 \\
\hline
\end{tabular}

A perusal of the data in Table 1 reveals that all investigated CPI-azaazulenes possess PAs greater than $245 \mathrm{kcal} \mathrm{mol}^{-1}$ and therefore, can be classified as superbases. Molecules 2-Ac and 3-Ac (azaazulenes substituted with the CPI group at positions 2 and 3, respectively) are the weakest bases in the series regardless of the protonation site, with a PA value of $\sim 257$, and a GB of $\sim 250 \mathrm{kcal} \mathrm{mol}^{-1}$. However, in 1-azaazulenes where the seven-membered ring is substituted at positions $4-8(n=4,5$, 6,7 , and 8 ), higher basicity is achieved. In these five molecules, the preferred site of protonation is always the azaazulene nitrogen $\left(\mathrm{N}_{\text {azaazulene }}\right)$ with PA values which are $11-17 \mathrm{kcal}$ $\mathrm{mol}^{-1}$ higher than those calculated for protonation of the CPI substituent. The nature of interaction induced by protonation differs for these two sites. As mentioned earlier, the protonation at $\mathrm{N}_{\mathrm{CPI}}$ results in aromatic stabilization of the three-membered ring (Scheme 2), while the basicity of $\mathrm{N}_{\text {azaazulene }}$ in substituted azaazulenes depends on the electrondonating effect of the substituents. Further, the protonation of the azaazulene nitrogen leads to the more efficient $\pi$-electron delocalization over the whole molecule, whereas in the case when nitrogen at the CPI is protonated, the delocalization is limited to the substituent. ${ }^{38}$ This assertion is corroborated by the changes of the bond length between the $\mathrm{N}_{\mathrm{CPI}}$ and adjacent carbon; in the $\mathrm{N}_{\text {azaazulene }}$ protonated systems, this bond length shortens upon protonation (from $\sim 1.38 \AA$ in a neutral molecule to $\sim 1.34 \AA$, Table $S 1$ ), while in $\mathrm{N}_{\mathrm{CPI}}$ protonated systems this bond elongates to the value of $1.43 \AA$ on average. Moreover, the survey of atomic charges at $\mathrm{N}_{\text {azazulene }}$ and $\mathrm{N}_{\mathrm{CPI}}$ before and after protonation, obtained by Hirshfeld population analysis, ${ }^{39}$ shows that reduction of the negative charge of nitrogen atom upon its protonation is different for these two sites (Table S2). For molecules $n$-Ac, $(n=4,5,6,7$, and 8) protonated at azaazulene nitrogen, the amount of reduction of negative charge of $\mathrm{N}_{\text {azaazulene }}$ is bigger, compared to the reduction of negative charge of the $\mathrm{N}_{\mathrm{CPI}}$ when protonation occurs at the substituent. The most basic molecule is 8-Ac with a PA $=272.9 \mathrm{kcal} \mathrm{mol}^{-1}$, followed by 4-Ac and 6-Ac with a PA of 267.0 and $266.8 \mathrm{kcal} \mathrm{mol}^{-1}$, respectively, and 5-Ac and 7-Ac compounds having a PA of 262.4 and $264.0 \mathrm{kcal} \mathrm{mol}^{-1}$, respectively.

Among the molecules protonated at CPI, the highest PA and GB are also achieved in 8-Ac. This is due to the additional stabilizing effect caused by a weak intramolecular hydrogen bond (IHB) established between the proton on the CPI and the nitrogen atom of the azaazulene ring (the length of the $\mathrm{H}$ bond is $2.03 \AA$, Figure 2). Given the positions of the

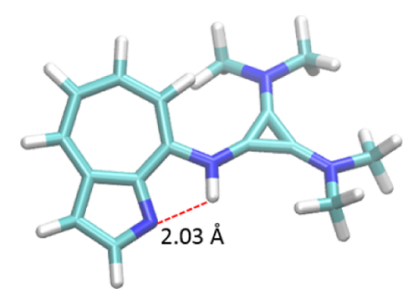

Figure 2. Optimized structure of the conjugate acid of molecule 8-Ac protonated at the substituent, with an intramolecular H-bond.

substituent, this interaction with a nitrogen of the azaazulene is not possible in other monosubtituted azaazulenes protonated at the substituent. To assess the strength of this IHB in 8-Ac protonated at the substituent, the AIM analysis ${ }^{40}$ was performed using the AIMall suite. ${ }^{41}$ According to the work of Afonin, ${ }^{42}$ the strength of IHB can roughly be estimated by the calculation of electron density $(\rho)$ at the bond critical point (BCP) of the IHB bond, using the following equation that represents improved Espinosa's equation ${ }^{42,43}$

$$
E_{\mathrm{HB}}\left(\rho^{\mathrm{BCP}}\right)=191.4 \rho^{\mathrm{BCP}}-1.78\left(\text { in } \mathrm{kcal} \mathrm{mol}^{-1}\right)
$$

The IHB strength in 8-Ac estimated by the AIM analysis and eq 7 is $3.3 \mathrm{kcal} \mathrm{mol}^{-1}$.

The calculated basicity of monosubstituted azaazulenes shows that substitution with one CPI group substantially increases the basicity of azaazulene by pushing electrons toward the nitrogen atom in the ring, thus making it more susceptible for protonation. Differences in basicity between azaazulenes substituted at different positions, although mild, suggest that the electron-donating effect of CPI is more pronounced when the substituent is placed at positions 4,6 , and 8 , than in the rest of the molecules. Because the inductive effect of the CPI affects the aromaticity of azaazulene, we explored how the position of the substituent influences the change of the aromaticity before and after the protonation, calculating nucleus-independent chemical shifts, $\operatorname{NICS}(1),{ }^{44}$ for the five- and seven-membered ring for the neutral and protonated forms of all monosubstituted 1-azaazulenes $\boldsymbol{n}$-Ac $(n$ $=2,3,4,5,6,7$, and 8 ). The results, presented in Table S3, reveal that for all molecules, the decrease in aromaticity upon protonation is more pronounced in the five-membered ring. Molecules 5-Ac and 7-Ac show the most noticeable loss of aromaticity, with a $\Delta \mathrm{NICS}(1)$ value of $5.6 \mathrm{ppm}$ (from -13.9 to -8.3 and -14.0 to $-8.4 \mathrm{ppm}$ going from the neutral to protonated form of the molecule), whereas for the other studied molecules $\Delta \mathrm{NICS}(1)$ is $\sim 4 \mathrm{ppm}$ or smaller. However, molecules 2-Ac and 3-Ac do not fit into this analysis; despite the mild loss of aromaticity caused by the proton, their basicity is significantly smaller when compared with other studied monosubstituted systems. According to the data from Table S2, the reduction of the negative charge of the protonation center in 2-Ac and 3-Ac $\left(\Delta q\left(\mathrm{~N}_{\text {azaazulen }}\right)\right.$, Table S2) is 
substantially smaller than that in the rest of the systems, implying the less efficient charge delocalization that inversely affects their basicity.

Double and triple substitution of 1-azaazulene with electrondonating groups should lead to a further increase in basicity. Because the placement of the electron-donating substituent at position 8 results in the most basic CPI-substituted 1azaazulene, followed by substitutions at positions 6 and 4, we have investigated two superbases containing two and three CPI groups, respectively, 6,8-disubstituted and 4,6,8-trisubstituted 1-azaazulene, as shown in Figure 3.

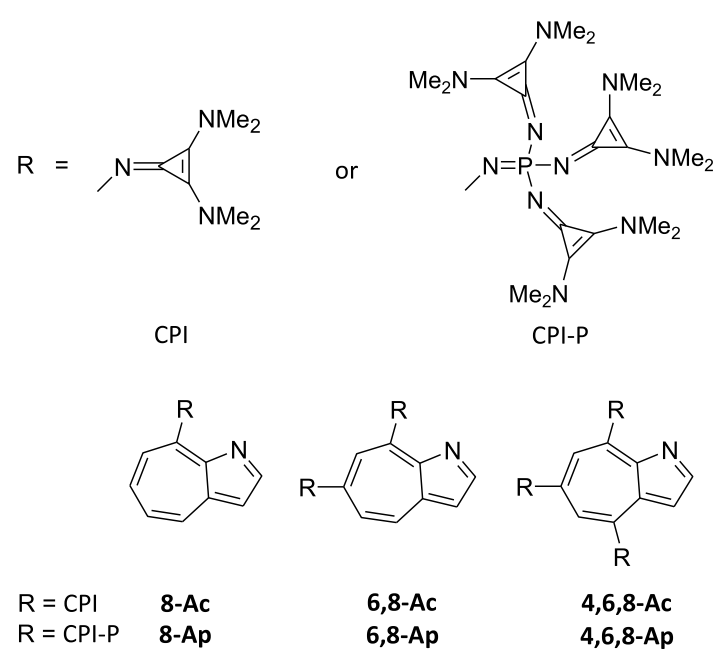

Figure 3. 1-Azaazulenes substituted with cyclopropenimino (CPI) and cyclopropeniminophosphazeno (CPI-P) groups.

The azaazulenes substituted with the cyclopropenimino group reached a PA of $290.7 \mathrm{kcal} \mathrm{mol}^{-1}(4,6,8-\mathrm{Ac})$ and a $\mathrm{p} K_{\mathrm{a}}$ in acetonitrile of 34.1 units, according to the CPCM model (Table 2). The change in PA upon substitution by one CPI

Table 2. Gas Phase PA, GBs of 1-Azaazulene and 1Azaazulenes Substituted with CPI and CPI-P Groups (Figure 3) and Their $\mathrm{pK}_{\mathrm{a}}$ Values in $\mathrm{MeCN}^{a}$

$\begin{array}{lcccc}\text { superbase } & \mathrm{PA} & \mathrm{GB} & \mathrm{p} K_{\mathrm{a}}^{\mathrm{IPCM}} & \mathrm{p} K_{\mathrm{a}}^{\mathrm{CPCM}} \\ \text { 1-azaazulene } & 239.5 & 231.9 & 18.3 & 17.6 \\ \text { 8-Ac } & 272.9 & 265.3 & 26.6 & 28.8 \\ \text { 6,8-Ac } & 282.8 & 276.1 & 30.0 & 32.1 \\ \text { 4,6,8-Ac } & 290.7 & 284.1 & 32.4 & 34.1 \\ \text { 8-Ap } & 296.5 & 291.2 & b & 38.1 \\ \text { 6,8-Ap } & 313.1 & 308.7 & b & 45.5 \\ \text { 4,6,8-Ap } & 319.2 & 316.9 & b & 47.5\end{array}$

${ }^{a} \mathrm{PA}$ and $\mathrm{GB}$ values are given in $\mathrm{kcal} \mathrm{mol}{ }^{-1} .{ }^{b}$ For these molecules, it was not possible to achieve convergence in IPCM calculation.

going from mono to disubstituted molecule is $9.9 \mathrm{kcal} \mathrm{mol}^{-1}$, whereas the increase in PA going from di to trisubstituted azaazulene is $8.9 \mathrm{kcal} \mathrm{mol}^{-1}$. This is a very slight difference in the enhancement of PA, but a certain reduction of basicity increase (upon addition of one more substituent) is expected because of a well-described phenomenon of saturation of substituent effects. ${ }^{45}$ Namely, the capacity of a molecular backbone to accept electron density brought by a substituent that acts as a strong electron donor is limited by the size of the backbone; therefore the increase in basicity is not linearly related to the increase of the number of electron donor groups.
Another substituent at 1-azaazulene that we considered is the cyclopropeniminophosphazeno group (designated here as CPI-P), obtained by a combination of phosphazene and dimethylaminocyclopropenimine and recently synthesized by Lambert. ${ }^{17 \mathrm{~b}}$ Cyclopropeniminophosphazene is more basic than dimethylaminocyclopropenimine (CPI), so we anticipated that 1-azaazulenes substituted with CPI-P could be substantially more basic than CPI-substituted azaazulenes. The calculated $\mathrm{PA}, \mathrm{GB}$, and $\mathrm{p} K_{\mathrm{a}}$ in acetonitrile of the most basic 1-azaazulenes substituted with CPI-P, shown in Figure 3, are also presented in Table 2. Because of a convergence problem in the IPCM model for such types of molecules, $\mathrm{p} K_{\mathrm{a}}$ values are calculated using the CPCM solvation model only, ${ }^{35}$ but results for superbases with the CPI substituent show that the $\mathrm{p} K_{\mathrm{a}}$ values obtained by CPCM are in acceptable agreement with those obtained with IPCM.

The presence of CPI-P in 1-azaazulene results in extremely strong superbases; the disubstituted azaazulene has a PA of $313.1 \mathrm{kcal} \mathrm{mol}^{-1}$, while the trisubstituted molecule exhibits even higher basicity with a PA of $319.2 \mathrm{kcal} \mathrm{mol}^{-1}$ and a $\mathrm{pK}$ in acetonitrile of 47.5 units. Thus, for azaazulenes with CPI-P, the overall increase of PA goes from $296.5 \mathrm{kcal} \mathrm{mol}^{-1}$ in the monosubstituted molecule (8-Ap) to $319.2 \mathrm{kcal} \mathrm{mol}^{-1}$ in the trisubstituted one $(4,6,8-A p)$. In comparison with CPIsubstituted azaazulenes, the saturation of the substituent effect here is less gradual; the first increment of PA (from mono to disubstituted) is $16.6 \mathrm{kcal} \mathrm{mol}^{-1}$, while the substitution by the third CPI-P group enhances the PA for an additional $6.1 \mathrm{kcal}$ $\mathrm{mol}^{-1}$ only. Although substitution of azaazulene with CPI-P results in very strong superbases, the bulkiness of CPI-P could cause steric problems when three substituents are present. To estimate a steric strain caused by the repulsions between the substituents, we compared the total energy of the three CPI-P groups (without the azaazulene unit) arranged identically as in optimized geometry of the superbase 4,6,8-Ap, and the total energy of the three molecules of cyclopropeniminophosphazenes at an infinite distance from each other (i.e., without any mutual interaction). A prearranged structure containing three CPI-P is by $17.3 \mathrm{kcal} \mathrm{mol}^{-1}$ less stable than three CPI-P groups at an infinite distance, and this destabilization can be attributed to the steric strain. Because the saturation of the substituent effect occurs upon substitution by the third CPI-P, we wondered whether the presence of the smaller, but less basic functional group CPI as a third substituent would result in a molecule of similar basicity as 4,6,8-Ap. It turns out that the 1azaazulene substituted by two CPI-P groups at positions 4 and 8 , and by one CPI group placed at position 6 (molecule 6c4,8-Ap, Figure 4), has a PA of $320.2 \mathrm{kcal} \mathrm{mol}^{-1}$, GB of 313.9 $\mathrm{kcal} \mathrm{mol}^{-1}$ and $\mathrm{p} K_{\mathrm{a}}$ in acetonitrile of 45.9 , thus being equally basic as 4,6,8-Ap.

3.2. Bis(1-azaazulen-2-yl)-methyl-amines and Tris(1azaazulen-2-yl)-amines with Cyclopropenimino and Cyclopropeniminophosphazeno Substituents. While a high steric strain does not directly influence the basicity (because the destabilization due to the bulkiness of substituents is roughly the same in a neutral and protonated molecule), it could pose difficulty during the synthesis of this type of superbases. To attenuate this problem, we decided to utilize two and three 1-azaazulene units in one molecule to act as a core unit in novel azaazulene superbases. Combining two or three azaazulene units in one molecule enables substitution with a larger number of electron-donating substituents per molecule, without further increase in steric strain. The bis(1- 

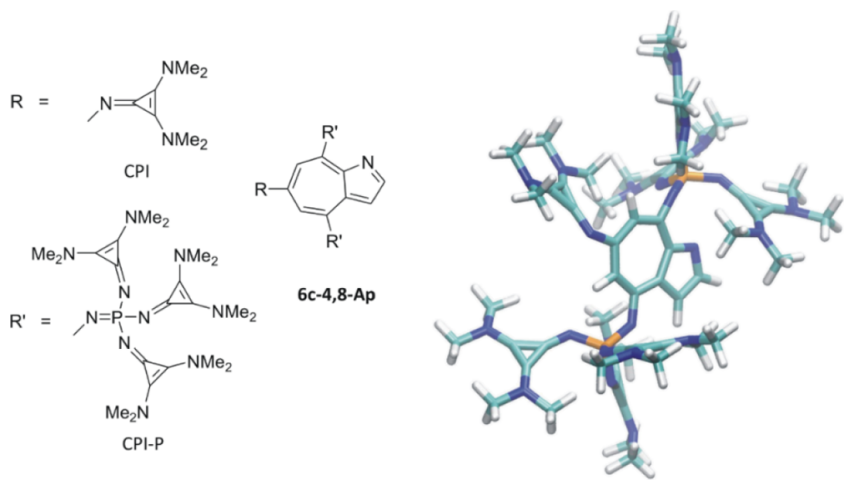

Figure 4. Left: Schematic representation of superbase 6c-4,8-Ap (4,6dicyclopropenimine phosphazeno-6-cyclopropenimino-1-azaazulene). Right: The optimized structure of the neutral form of the $6 \mathrm{c}-4,8-\mathrm{Ap}$.

azaazulen-2-yl)-methyl-amine and tris(1-azaazulen-2-yl)-amine (in further text: bis-azaazulenyl and tris-azaazulenyl, respectively) were employed as a molecular backbone for superbases that contain two and three 1-azaazulenes, respectively. New superbases with bis- and tris-azaazulenyl amines are substituted with CPI and CPI-P, as schematically represented in Figure 5.

Calculated values of PAs, GBs, and $\mathrm{p} K_{\mathrm{a}}$ values in acetonitrile for bis- and tris-azaazulenyl derivatives substituted with CPI and CPIP-P are listed in Table 3. Superbases with two azaazulene units (bis-azaazulenyls) containing cyclopropenimino group (CPI) do not exhibit a significant increase in basicity compared to superbases with one 1-azaazulene. For example, isomers 4-Bc and 6-Bc with two CPI groups have PAs of 284.9 and $282.3 \mathrm{kcal} \mathrm{mol}^{-1}$, respectively, similar to disubstituted 1-azaazulene 6,8-Ac whose PA is $282.8 \mathrm{kcal}$ $\mathrm{mol}^{-1}$ (Table 2). However, the presence of two azaazulene units in a molecule makes possible substitution with four CPI groups (at positions 4 and 6 of each azaazulene) without steric problems, which results in increased basicity for tetrasubstituted superbase 4,6-Bc, with a PA of $297 \mathrm{kcal} \mathrm{mol}^{-1}$ and $\mathrm{p} K_{\mathrm{a}}$ in $\mathrm{MeCN}$ of 36.0 units.

Protonation of bis-azaazulenyl occurs at one of the two present azaazulenes, each of them carrying its substituent(s).
Table 3. Gas Phase PAs, GBs of Bis(1-azaazulen-2-yl)methyl-amines and Tris(1-azaazulen-2-yl)-amines Substituted with Cyclopropenimino and Cyclopropeniminophosphazeno Group, and Their $\mathrm{pK}$ Values in $\mathrm{MeCN}^{a}$

\begin{tabular}{lccc} 
superbase & $\mathrm{PA}$ & $\mathrm{GB}$ & $\mathrm{p} K_{\mathrm{a}}^{\mathrm{CPCM}}$ \\
\hline 4-Bc & 284.9 & 277.1 & 29.7 \\
6-Bc & 282.3 & 275.0 & 28.8 \\
4,6-Bc & 297.0 & 289.2 & 36.0 \\
6-Tc & 293.1 & 286.2 & 30.7 \\
4,6-Tc & 306.8 & 301.6 & 35.1 \\
4-Bp & 301.7 & 294.4 & 34.5 \\
6-Bp & 305.4 & 299.6 & 33.9 \\
4,6-Bp & 322.8 & 318.4 & 45.7 \\
6-Tp & 319.0 & 312.8 & 36.3 \\
4,6-Tp & 335.2 & 333.5 & 50.0 \\
4 & &
\end{tabular}

${ }^{a} \mathrm{PA}$ and $\mathrm{GB}$ values given in $\mathrm{kcal} \mathrm{mol}^{-1}$.

In that arrangement, the electron-donating group(s) placed at the second, not protonated azaazulene core, have a smaller influence to the basicity of the system, compared to substituted 1 -azaazulenes (Figure 3) where all the substituents are attached to the same molecule of azaazulene, and the inductive effect of substituents is more pronounced. Therefore, the basicity of disubstituted bis-azaazulenyls, $4-\mathbf{B c}$ and $6-\mathbf{B c}$, is expected to be lower than that in disubstituted 1-azaazulene, 6,8-Ac. However, the reduction of an inductive effect that adversely affects the basicity of bisazaazulenyls is compensated by the presence of IHB in the protonated form of molecules 4Bc and 6-Bc. Although the most stable conformation of the neutral form of bis-azaazulenyl derivatives corresponds to the schematic presentation in Figure 5 (where repulsions between lone electron pairs at nitrogen atoms in the five-membered rings are avoided), the optimal conformer in the protonated form possesses IHB that occurs after the rotation of one of the azaazulenes around the $\mathrm{C}-\mathrm{N}\left(\mathrm{sp}^{3}\right)$ bond, as shown in Scheme 4 for molecule 6-Bc.

The calculated enthalpy barrier for bond rotation shown in Scheme 4 is low $\left(2.0 \mathrm{kcal} \mathrm{mol}^{-1}\right)$, implying that it occurs
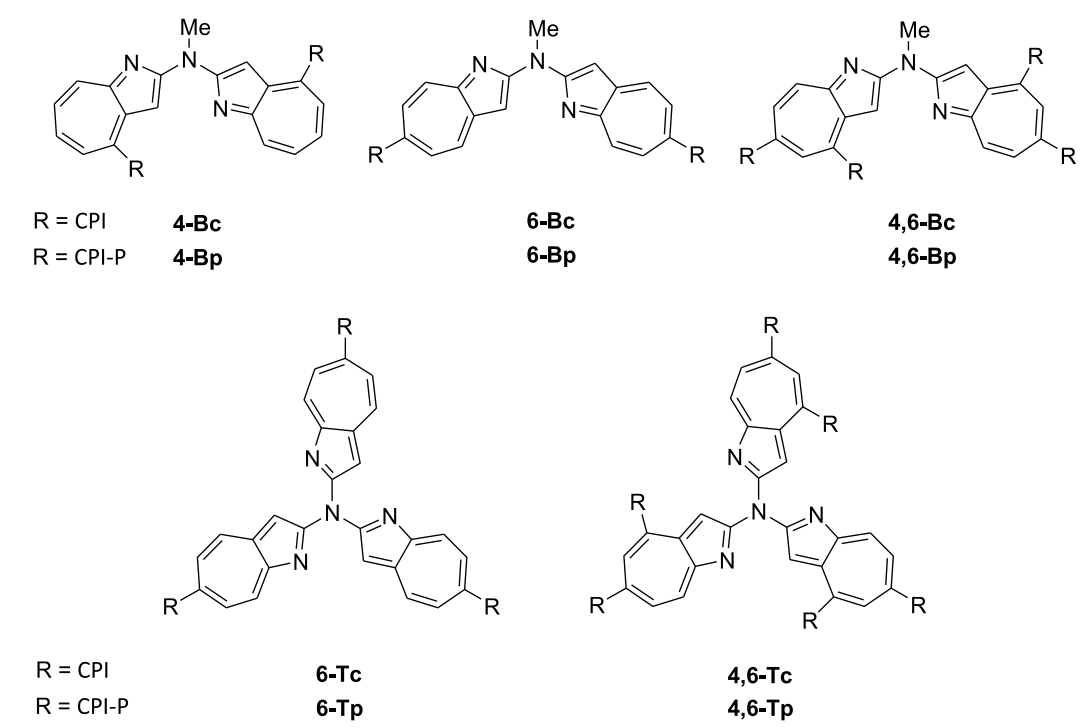

Figure 5. Bis(1-azaazulen-2-yl)-methyl-amine and tris(1-azaazulen-2-yl)-amine substituted with cyclopropenimino (CPI) and cyclopropenimino phosphazeno (CPI-P) group. 
Scheme 4. Protonation of Bis-Azaazulenyl and Subsequent Rotation of One Azaazulene Unit Around the $\mathrm{C}-\mathrm{N}\left(\mathrm{sp}^{3}\right)$ Bond, Enabling More Stable Conformation of the Conjugate Acid
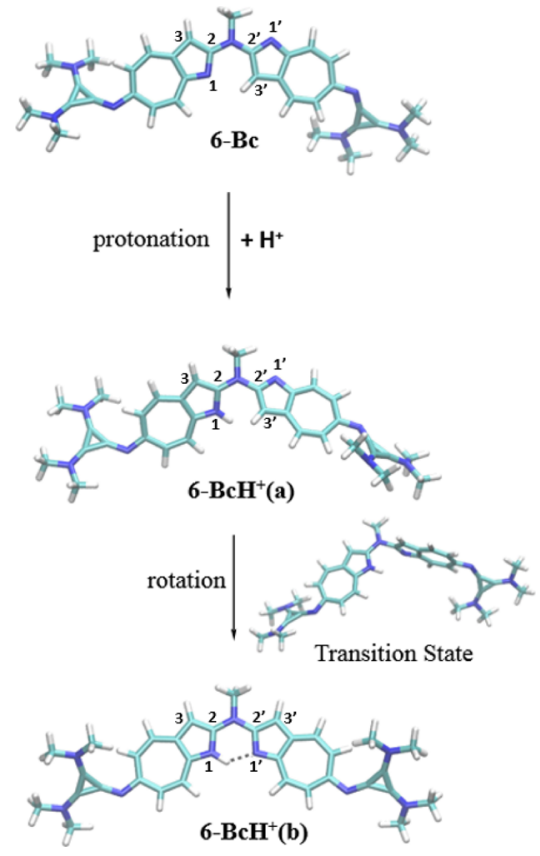

spontaneously at $298 \mathrm{~K}$. The difference in thermodynamic stability between $6-\mathrm{BcH}^{+}(\mathbf{a})$ and $\mathbf{6}-\mathrm{BcH}^{+}(\mathbf{b})$ is $7.5 \mathrm{kcal} \mathrm{mol}^{-1}$. The conformer $\mathbf{6}-\mathrm{BcH}^{+}(\mathbf{b})$ enables the formation of the intramolecular $\mathrm{H}$-bond between the hydrogen at $\mathrm{N}(1)$ and nitrogen $\mathrm{N}\left(1^{\prime}\right)$ of the neighboring azaazulenyl unit, which stabilizes the protonated form of the superbase and has a positive effect on its basicity. The length of this IHB in 6$\mathrm{BcH}^{+}(\mathbf{b})$ is $1.82 \AA$, and its estimated strength is $6.3 \mathrm{kcal} \mathrm{mol}^{-1}$ (obtained utilizing AIM analysis and eq 7). The presence of IHB represents the main contribution to the stability difference between (a) and (b). In the less stable conformer $\mathbf{6}-\mathbf{B c H}^{+}(\mathbf{a})$, two hydrogen atoms, one at the $\mathrm{N}(1)$ and the other at the $\mathrm{C}\left(3^{\prime}\right)$, are placed at a distance of $2.17 \AA$, which is close to the sum of van der Waals radii $(2.4 \AA)$, implying that the interaction between them could be attractive. However, the AIM analysis showed the absence of the BCP between these two hydrogens. Tetrasubstituted bisazaazulenyl $4,6-\mathbf{B c H}^{+}$ behaves similarly to $6-\mathrm{BcH}^{+}$, with a stability difference between conformers (a) and (b) of $7.4 \mathrm{kcal} \mathrm{mol}^{-1}$ and enthalpy barrier for rotation of azaazulene of only $3.3 \mathrm{kcal} \mathrm{mol}^{-1}$. The length of

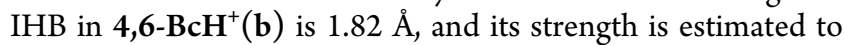
be $6.0 \mathrm{kcal} \mathrm{mol}{ }^{-1}$. In conformer $4,6-\mathrm{BcH}^{+}(\mathrm{a})$, the distance between hydrogen atoms at $\mathrm{N}(1)$ and $\mathrm{C}\left(3^{\prime}\right)$ is $2.12 \AA$, and AIM analysis did not find a BCP between them.

For CPI-P substituted bis-azaazulenyls, the most stable protonated conformers are those with an intramolecular $\mathrm{H}$ bond, analogous to CPI derivatives. The rotation of azaazulenyl needed for the formation of this IHB occurs spontaneously in protonated $4-\mathrm{Bp}$ and $\mathbf{6 - B p}$ because calculations predict a negligible enthalpy barrier $(1.8 \mathrm{kcal}$ $\mathrm{mol}^{-1}$ for 6-Bp). However, contrary to CPI-disubstituted bisazaazulenyls where the intramolecular $\mathrm{H}$-bond in a protonated form of the molecule compensates a less efficient inductive effect of the substituent, disubstituted CPI-P bis-azaazulenyls 4-Bp and 6-Bp (PA $=301.7$ and $305.9 \mathrm{kcal} \mathrm{mol}^{-1}$, respectively) have lower basicity compared to analogous disubstituted 1-azaazulene 6,8-Ap whose PA is $313.1 \mathrm{kcal}$ $\mathrm{mol}^{-1}$. Besides the less pronounced inductive effect of the substituent placed at the second azaazulenyl unit, there is an additional stabilization of the protonated 6,8-Ap-the intramolecular H-bond between the proton and the nitrogen atom of the substituent-whose strength is estimated to be $3.9 \mathrm{kcal}$ $\mathrm{mol}^{-1}$. Therefore, in protonated forms of $4-\mathrm{Bp}$ and 6-Bp, the stabilizing influence of IHB occurring in the more stable rotamer is not high enough to overcome two stabilizing effects that are present in protonated 6,8-Ap: the more efficient inductive effect of two CPI-P placed at the same azaazulene and intramolecular $\mathrm{H}$-bond between the proton and the nitrogen of the substituent. Finally, bisazaazulenyl substituted with four CPI-P groups, 4,6-Bp, expectedly has very large basicity, with a PA of over $322 \mathrm{kcal} \mathrm{mol}^{-1}$ and a $\mathrm{pK}_{\mathrm{a}}$ of 45.7 . Again, the rotation of one azaazulene unit is needed so that a more stable conformer of the protonated superbase is achieved, and the enthalpy barrier for this rotation is predicted to be only $1.2 \mathrm{kcal} \mathrm{mol}^{-1}$.

The trisazaazulenyl superbase, a molecule with three CPI groups 6-Tc, whose PA is $293.1 \mathrm{kcal} \mathrm{mol}^{-1}$, is slightly more basic than the analogous trisubstituted monoazaazulene 4,6,8Ac $\left(\mathrm{PA}=290.7 \mathrm{kcal} \mathrm{mol}^{-1}\right)$. Superbase 6-Tc in a protonated state possesses one IHB; its calculated strength is estimated to be $6.6 \mathrm{kcal} \mathrm{mol}^{-1}$. With a PA of $306.8 \mathrm{kcal} \mathrm{mol}^{-1}$ superbase 4,6-Tc containing six CPI groups (i.e., two substituents per azaazulene unit) has the highest basicity among CPIsubstituted superbases studied in this work. In cyclopropeniminophosphazeno tris-azaazulenyls, trisubstituted superbase, 6-Tp, is equally basic as its counterpart with one azaazulene 4,6,8-Ap, whereas molecule 4,6-Tp containing six CPI-P groups achieves an extremely high PA of even $335.2 \mathrm{kcal}$ $\mathrm{mol}^{-1}$. Similar to bis-azaazulenyls, in tris-azaazulenyls the most stable conformation of a neutral molecule differs from the most stable protonated conformer. We examined rotation barriers in the conjugate acid, and it turns out that rotation occurs spontaneously with activation enthalpies of 6.4 and $3.0 \mathrm{kcal}$ $\mathrm{mol}^{-1}$ for 6-Tc and 4,6-Tc, respectively. For CPI-P substituted tris-azaazulenyls the values of energy barriers were estimated from a scan, without exact localization of TS on PES, and their approximate values are 1.0 and $4.0 \mathrm{kcal} \mathrm{mol}^{-1}$ for $6-\mathrm{Tp}$ and 4,6-Tp, respectively.

Bis- and tris-azaazulenyls are systems where double protonation is possible. Calculation of the second PAs in a gas phase (PA(II)) for bis- and tris-azaazulenyls showed that CPI-substituted systems studied here have a PA(II) lower than $245.3 \mathrm{kcal} \mathrm{mol}^{-1}$ (superbasicity criterion), except the molecule 4,6-Tc with a value of $249.6 \mathrm{kcal} \mathrm{mol}^{-1}$. For CPI-P substituted systems, the criterion of superbasicity for the second protonation is satisfied in molecules 4,6-Bp, 6- Tp, and 4,6Tp, and their PA(II) values are 262.3, 262.7, and $277.3 \mathrm{kcal}$ $\mathrm{mol}^{-1}$, respectively. For tris-azaazulenyls, even triple protonation may occur. Calculated values of PA(III) for 6-Tp and 4,6-Tp are 213.0 and $247.7 \mathrm{kcal} \mathrm{mol}^{-1}$, respectively.

Finally, to evaluate the kinetic basicity of some of the novel superbases presented in this work, we calculated the activation free energy for the reaction of proton transfer between the protonated and neutral form of the same superbase. Although new superbases structurally do not correspond to typical proton sponges, there are several possibilities for intramolecular H-bonds to be formed upon protonation; therefore, it is of interest to explore how this feature affects the kinetics of 
proton release. For this analysis, we selected CPI-disubstituted 1-azaazulene and CPI-disubstituted bisazaazulenyl (superbases 6,8-Ac and 6-Bc). For the sake of comparison, the activation free energy for the analogous reaction of the proton sponge DMAN is also calculated. The activation free energy for the proton exchange between the protonated and neutral form of DMAN (Scheme 5) is $41.2 \mathrm{kcal} \mathrm{mol}^{-1}$. Such a high barrier indicates that deprotonation of a conjugate acid is very slow, which is in agreement with the observed slow kinetics of proton sponges. $^{21}$

Scheme 5. Proton Exchange between the Conjugate Acid and Neutral Form of DMAN
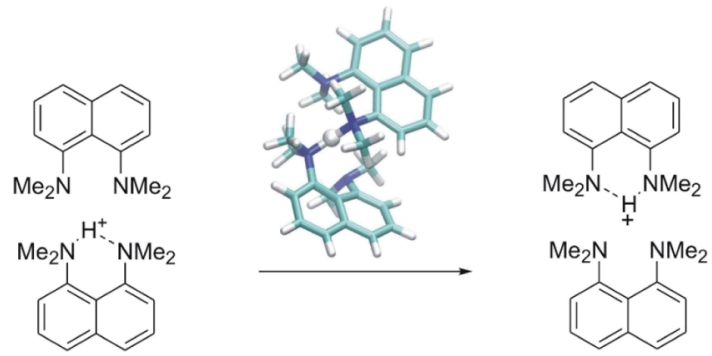

Contrary to the proton sponge DMAN, the energy barrier for the reaction of proton exchange between the protonated and neutral superbase $\mathbf{6 , 8 - A c}$ is very low, with calculated

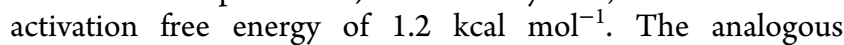
reaction for molecule 6-Bc also occurs spontaneously, with a calculated free energy barrier of $1.1 \mathrm{kcal} \mathrm{mol}^{-1}$. Figure 6 shows optimized transition states for proton exchange between the protonated and neutral form of the same molecule, for 6,8-Ac, and 6-Bc.

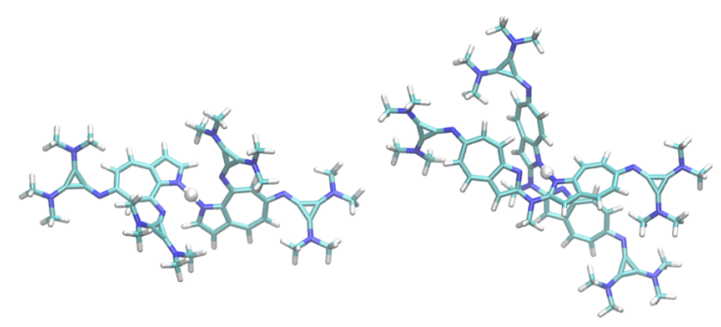

Figure 6. Optimized structures of the transition state for proton transfer between protonated to neutral 6,8-disubstituted 1-azaazulene 6,8-Ac (left) and 6,6'-disubstituted bis(1-azaazulen-2-yl)-methylamine, 6-Bc (right).

For this reaction, the transition state that corresponds to transfer of a proton from the protonated superbase to a neutral one is localized at PES and connected with both the minima by calculating the intrinsic reaction coordinate. The frequency of imaginary vibration that corresponds to the proton transfer between the protonated and neutral molecule is -1171.8 and $-1213.8 \mathrm{~cm}^{-1}$ for $6,8-\mathrm{Ac}$ and $6-\mathrm{Bc}$, respectively (for comparison, the frequency of the imaginary mode for proton exchange in DMAN is $-1169.4 \mathrm{~cm}^{-1}$ ). Such low activation energy implies that the release of a proton in this type of superbases occurs very easily.

\section{CONCLUSIONS}

Dimethylcyclopropenimino- and dimethylcyclopropeniminophosphazeno-based substituents that act as strong electron donors were employed in the design of novel superbases using one and combined two or three 1-azaazulenes as a core unit. The maximum basicity of azaazulene-based compounds is achieved when substituents are placed at positions 4,6 , and 8 of azaazulene, due to the most favorable distribution of electron density that makes the nitrogen atom in the azaazulene ring more negative and thus increases the basicity of the molecule. In molecules based on one azaazulene unit, substitution with CPI yields superbases with the calculated PA in a range from 272.9 to $290.7 \mathrm{kcal} \mathrm{mol}^{-1}$ and $\mathrm{p} K_{\mathrm{a}}$ in $\mathrm{MeCN}$ from 28.8 to 34.1 units. The presence of the same substituent in compounds containing two azaazulenes as a scaffold resulted in slightly stronger superbases with PA values from 282.3 to $297 \mathrm{kcal} \mathrm{mol}^{-1}$ and $\mathrm{p} K_{\mathrm{a}}$ in $\mathrm{MeCN}$ from 28.8 to 36, whereas the strongest superbase with CPI is trisazaazulenyl containing six cyclopropenimino groups (4,6-Tc) with a PA of almost 307 $\mathrm{kcal} \mathrm{mol}^{-1}$. Although the expansion of a core unit that carries electron-donating groups enables substitution with a larger number of substituents and therefore leads to an increase in basicity, this dependence is not linear. This is related to the saturation of the substituent effect, but it is also a consequence of the fact that the strongest electron-donating effect originates from substituent(s) placed at the same azaazulene where protonation occurs, whereas the rest of present groups placed to the second and third azaazulenyls have a smaller influence on the system. The important factor that increases the basicity of bis- and tris-azazulenyl superbases is the IHB between the proton and nitrogen atom that belongs to the neighboring azaazulene that occurs in the protonated form of these superbases, regardless of the substituent type. Substitution with the CPI-P group expectedly resulted in a very high superbasicity; for molecules with one azaazulene the PA was as high as $319.2 \mathrm{kcal} \mathrm{mol}^{-1}$ and $\mathrm{pK}$ in $\mathrm{MeCN}$ was estimated at 47.5 units. The most basic bisazaazulenyl with four CPI-P substituents has a PA of $322.8 \mathrm{kcal} \mathrm{mol}^{-1}$ and $\mathrm{p} K_{\mathrm{a}}$ in $\mathrm{MeCN}$ of 45.7 , whereas the strongest superbase proposed in this work is tris-azaazulenyl substituted with six cycloropeniminephosphazeno groups, 4,6-Tp, with a PA as high as $335.2 \mathrm{kcal} \mathrm{mol}^{-1}$ and a $\mathrm{pK}_{\mathrm{a}}$ of 50 .

The investigation of reaction kinetics for the proton transfer between the neutral and protonated form of the same molecule (dicyclopropenimino-1-azaazulene, 6,8-Ac, and 6,6'-dicyclopropenimino bis(1-azaazulen-2-yl)-methyl-amine, 6-Bc) shows that, unlike in proton sponges, the reaction of deprotonation has a small activation energy, so their kinetic basicity is also high - not only the protonation but also a release of the proton from the protonated base occurs very easily, which makes them suitable for reactions where fast proton exchange is needed.

Although some of the proposed compounds show remarkable basicity, their possible application as deprotonating agents in organic syntheses could be limited by their bulkiness and size. However, unlike the small superbase, the bulky one would be able to generate the "naked anion", which is often needed as an activation step during organic syntheses.

Given the presence of conjugated $\pi$ electrons in azaazulene, the further theoretical investigation of spectroscopic properties of the designed molecules is planned to reveal whether the protonation causes the change of UV/vis spectra, which would lead to the application of these systems as $\mathrm{pH}$ sensors. Because the paths for the synthesis of 1-azaazulene derivatives are already known, ${ }^{28-31}$ and having in mind that both dimethylamino-cyclopropemenimines ${ }^{16}$ as well as higherorder cyclopropenimino superbases and cyclopropenimino- 
phosphazenes, ${ }^{17 \mathrm{~b}}$ can be efficiently synthesized, we believe that new superbases should be recognized as targets for synthesis and possible application.

\section{ASSOCIATED CONTENT}

\section{S Supporting Information}

The Supporting Information is available free of charge on the ACS Publications website at DOI: 10.1021/acsomega.9b02087.

Cartesian coordinates, energies, thermal corrections to enthalpy and thermal corrections to free energy for the neutral and protonated form of all the presented superbases: CPI and CPI-P substituted 1-azaazulenes, bis(1-azaazulen-2-yl)-methyl-amines, and tris(1-azaazulen-2-yl)-amines. Cartesian coordinates, energies and thermal corrections to free energy for minima and transition states for proton transfer reactions for DMAN, di-CPI-1-azaazulene, and mono-CPI-bis(1-azaazulen-2yl)-methyl-amine, relevant bond lengths, atomic charges at protonation sites, and NICS(1) values for monosubstituted cyclopropen1-azaazulenes (PDF)

\section{AUTHOR INFORMATION}

\section{Corresponding Author}

*E-mail: dbaric@irb.hr. Phone: +385 14571385.

ORCID $\odot$

Danijela Barić: 0000-0002-5614-5167

Notes

The author declares no competing financial interest.

\section{ACKNOWLEDGMENTS}

The computational resources were provided by the University of Zagreb Computing Centre (SRCE), and the Croatian National Grid Infrastructure (CRO-NGI).

\section{REFERENCES}

(1) Ishikawa, T.; Margetić, D. In Perspectives//Superbases for Organic Synthesis Guanidines, Amidines, Phosphazenes and Related Organocatalysts; Ishikawa, T., Ed.; John Wiley \& Sons Ltd: Chichester, West Sussex, 2009.

(2) (a) Decouzon, M.; Gal, J.-F.; Maria, P.-C.; Raczyńska, E. D. Superbases in the gas phase: Amidine and guanidine derivatives with proton affinities larger than $1000 \mathrm{kj} \mathrm{mol}^{-1}$. Rapid Commun. Mass Spectrom. 1993, 7, 599-602. (b) Raczyńska, E. D.; Maria, P.-C.; Gal, J.-F.; Decouzon, M. Superbases in the gas phase. Part II. Further extension of the basicity scale using acyclic and cyclic guanidines. $J$. Phys. Org. Chem. 1994, 7, 725-733. (c) Raczynska, E. D.; Decouzon, M.; Gal, J.-F.; Maria, P.-C.; Wozniak, K.; Kurg, R.; Carins, S. N. Superbases and superacids in the gas phase. Trends in Org. Chem. 1998, 7, 95-103.

(3) Caubere, P. Unimetal super bases. Chem. Rev. 1993, 93, 23172334.

(4) Raczyńska, E. D.; Gal, J.-F.; Maria, P.-C. Enhanced basicity of push-pull nitrogen base in the gas phase. Chem. Rev. 2016, 116, 13454-13511.

(5) Kögel, J. F.; Margetić, D.; Xie, X.; Finger, L. H.; Sundermeyer, J. A phosphorus bisylide: exploring a new class of superbases with two interacting carbon atoms as basicity centers. Angew. Chem. Int. Ed. 2017, 56, 3090-3093.

(6) Tang, J.; Dopke, J.; Verkade, J. G. Synthesis of new exceedingly strong non-ionic bases: $\mathrm{RN}: \mathrm{P}\left(\mathrm{MeNCH}_{2} \mathrm{CH}_{2}\right)_{3} \mathrm{~N}$. J. Am. Chem. Soc. 1993, 115, 5015-5020.

(7) (a) Mehlmann, P.; Mück-Lichtenfeld, C.; Tan, T. T. Y.; Dielmann, F. Tris(imidazolin 2-ylidenamino)phosphine: A crystalline
phosphorus(III) superbase that splits carbon dioxide. Chem.-Eur. J. 2017, 23, 5929-5933. (b) Ullrich, S.; Kovačević, B.; Xie, X.; Sundermeyer, J. Phosphazenyl phosphines: the most electron-rich uncharged phosphorus Brønsted and Lewis bases. Angew. Chem. Int. Ed. 2019, 58, 10335-10339.

(8) (a) Biswas, A. K.; Lo, R.; Ganguly, B. First principles studies toward the design of silylene superbases: a density functional theory study. J. Phys. Chem. A 2013, 117, 3109-3117. (b) Biswas, A. K.; Lo, R.; Si, M. K.; Ganguly, B. Superbasicity of silylene derivatives achieved via non-covalent intramolecular cation $\cdots \pi$ interactions and exploited as molecular containers for $\mathrm{CO}_{2}$. Phys. Chem. Chem. Phys. 2014, 16, 12567-12575. (c) Biswas, A. K.; Si, M. K.; Ganguly, B. The effect of $\sigma / \pi, \sigma$ and $\pi$ donors on the basicity of silylene superbases: a density functional theory study. New J. Chem. 2018, 42, 11153-11159.

(9) Maksić, Z. B.; Kovačević, B.; Vianello, R. Advances in determining the absolute proton affinities of neutral organic molecules in the gas phase and their interpretation: a theoretical account. Chem. Rev. 2012, 112, 5240-5270.

(10) Fraser, R. R.; Mansour, T. S.; Savard, S. Acidity measurements on pyridines in tetrahydrofuran using lithiated silylamines. J. Org. Chem. 1985, 50, 3232-3234.

(11) (a) Hafelinger, G.; Kuske, F. K. H. General and theoretical aspects of amidines and related compounds. In The Chemistry of Amidines and Imidates; Patai, S., Rappoport, Z., Eds.; John Wiley \& Sons Ltd: Chichester, 1991; Vol. 2, pp 3-100. (b) Oszczapowicz, J. Basicity, H-bonding, tautomerism and complex formation of imidic acid derivatives. In The Chemistry of Amidines and Imidates; Patai, S., Rappoport, Z., Eds.; John Wiley \& Sons Ltd: Chichester, 1991; Vol. 2, pp 623-688.

(12) (a) Ishikawa, T.; Isobe, T. Modified guanidines as chiral auxiliaries. Chem.-Eur. J. 2002, 8, 552-557. (b) Gund, P. Guanidine, trimethylenemethane and Y-delocalization. Can acyclic compounds have aromatic stability? J. Chem. Ed. 1972, 49, 100-103. (c) Gobbi, A.; Frenking, G. Y-conjugated compounds: The equilibrium geometries and electronic structures of guanidine, guanidinium cation, urea and 1,1-diaminoethylene. J. Am. Chem. Soc. 1993, 115, 23632372. (d) Raczyńska, E. D.; Cyrański, M. K.; Gutowski, M.; Rak, J.; Gal, J.-F.; Maria, P.-C.; Darowska, M.; Duczmal, K. Consequences of proton transfer in guanidine. J. Phys. Org. Chem. 2003, 16, 91-106. (e) Yamamoto, Y.; Kojima, S. Synthesis and chemistry of guanidine derivatives. In The chemistry of amidines and imidates; Patai, S., Rappoport, Z., Eds.; John Wiley \& Sons Ltd: Chichester, 1991; Vol. 2, pp 485-526.

(13) (a) Schwesinger, R.; Schlemper, H. Peralkylated polyaminophosphazenes - extremely strong, neutral nitrogen bases. Angew. Chem. Int. Ed. Engl. 1987, 26, 1167-1169. (b) Schwesinger, R Organophosphorus reagents: a practical approach in chemistry. Nachr. Chem. Tech. Lab. 1990, 38, 1214-1226. (c) Schwesinger, R.; Willaredt, J.; Schlemper, H.; Keller, M.; Schmitt, D.; Fritz, H. Novel, very strong, uncharged auxiliary bases; design and synthesis of monomeric and polymer-bound triaminoiminophosphorane bases of broadly varied steric demand. Chem. Ber. 1994, 127, 2435-2454. (d) Schwesinger, R.; Schlemper, H.; Hasenfratz, C.; Willaredt, J.; Dambacher, T.; Breuer, T.; Ottaway, C.; Fletschinger, M.; Boele, J.; Fritz, H.; Putzas, D.; Rotter, H. W.; Bordwell, F. G.; Satish, A. V.; Ji, G.-Z.; Peters, E. M.; Peters, K.; von Schnering, H. G.; Walz, L. Extremely strong, uncharged auxiliary bases; monomeric and polymer-supported polyaminophosphazenes $\left(\mathrm{P}_{2}-\mathrm{P}_{5}\right)$. Liebigs Ann. 1996, 1055-1081. (e) Kaljurand, I.; Rodima, T.; Leito, I.; Koppel, I. A.; Schwesinger, R. Self-consistent spectrophotometric basicity scale in acetonitrile covering the range between pyridine and DBU. J. Org. Chem. 2000, 65, 6202-6208.

(14) (a) Despotović, I.; Kovačević, B.; Maksić, Z. B. Pyridine and striazine as building blocks of nonionic organic superbases - a density functional theory B3LYP study. New J. Chem. 2007, 31, 447-457. (b) Kovačević, B.; Despotović, I.; Maksić, Z. B. In quest of strong neutral organic bases and superbases - supramolecular systems containing four pyridine subunits. Tetrahedron Lett. 2007, 48, 261264. (c) Bachrach, S. M.; Wilbanks, C. C. Using the pyridine and 
quinuclidine scaffolds for superbases: a DFT study. J. Org. Chem. 2010, 75, 2651-2660. (d) Uchida, N.; Kuwabara, J.; Taketoshi, A.; Kanbara, T. Molecular design of organic superbases, azacalix $[3](2,6)$ pyridines: catalysts for 1,2- and 1,4-additions. J. Org. Chem. 2012, 77, 10631-10637. (e) Schröder, J.; Himmel, D.; Böttcher, T. 2,6Bis(diazaboryl)pyridine: A Superbasic Sterically Demanding Pyridine Ligand. Chem.-Eur J. 2017, 23, 10763-10767.

(15) (a) Verkade, J. G. Atranes: new examples with unexpected properties. Acc. Chem. Res. 1993, 26, 483-489. (b) Verkade, J. G. Main group atranes: chemical and structural features. Coord. Chem. Rev. 1994, 137, 233-295. (c) Wróblewski, A. E.; Pinkas, J.; Verkade, J. G. Strongly basic proazaphosphatranes: $\mathrm{P}\left(\mathrm{EtNCH}_{2} \mathrm{CH}_{2}\right)_{3} \mathrm{~N}$ and $\mathrm{P}\left(\text { iso- } \mathrm{PrNCH}_{2} \mathrm{CH}_{2}\right)_{3} \mathrm{~N}$. Main Group Chem. 1995, 1, 69-79. (d) Verkade, J. G. $\mathrm{P}\left(\mathrm{RNCH}_{2} \mathrm{CH}_{2}\right)_{3} \mathrm{~N}$ as very strong non-ionic bases and catalysts: recent advances and applications. Phosphorus, Sulfur, Silicon Relat. Phosphorus, Sulfur, Silicon Relat. Elem. 2002, 177, 1621-1631. (e) Verkade, J. G. $\mathrm{P}\left(\mathrm{RNCH}_{2} \mathrm{CH}_{2}\right)_{3} \mathrm{~N}$ : Very strong nonionic bases useful in organic synthesis. New Aspects Phosphorus Chem II. Topics in Current Chemistry; Springer, 2003; Vol. 223, pp 144. (f) Verkade, J. G.; Kisanga, P. B. Recent applications of proazaphosphatranes in organic synthesis. Aldrichimica Acta 2004, 37, 3-14.

(16) (a) Maksić, Z. B.; Kovačević, B. Spatial and electronic structure of highly basic organic molecules: cyclopropenimines and some related systems. J. Phys. Chem. A 1999, 103, 6678-6684. (b) Gattin, Z.; Kovačević, B.; Maksić, Z. B. Cooperative intramolecular hydrogen bonding effect and basicity - an ab initio and DFT study of the superbasic properties of $\mathrm{N}$-[(dimethylamino)alkyl]-2,3-diaminocycloprop-2-ene-1 imines. Eur. J. Org. Chem. 2005, 3206-3213. (c) Bandar, J. S.; Lambert, T. H. Enantioselective Brønsted base catalysis with chiral cyclopropenimines. J. Am. Chem. Soc. 2012, 134, 5552-5555. (d) Lambert, T. H.; Bandar, J. Aminocyclopropenium ions: synthesis, properties, and applications. Synthesis 2013, 45, 2485-2498. (e) Bandar, J. S.; Barthelme, A.; Mazori, A. Y.; Lambert, T. H. Structure-activityrelationship studies of cyclopropenimines as enantioselective Brønsted base catalysts. Chem. Sci. 2015, 6, 15371547.

(17) (a) Kovačević, B.; Maksić, Z. B.; Vianello, R. The proton affinity of some extended $\pi$-systems involving guanidine and cyclopropenimine subunits. J. Chem. Soc. Perkin Trans. 2 2001, 886-891. (b) Nacsa, E. D.; Lambert, T. H. Higher-order cyclopropenimine superbases: direct neutral Brønsted base catalyzed Michael reactions with $\alpha$-aryl esters. J. Am. Chem. Soc. 2015, 137, 10246-10253.

(18) (a) Kolomeitsev, A. A.; Koppel, I. A.; Rodima, T.; Barten, J.; Lork, E.; Röschenthaler, G.-V.; Kaljurand, I.; Kütt, A.; Koppel, I.; Mäemets, V.; Leito, I. Guanidinophosphazenes: design, synthesis, and basicity in THF and in the gas phase. J. Am. Chem. Soc. 2005, 127, 17656-17666. (b) Kovačević, B.; Maksić, Z. B. High basicity of tris(tetramethylguanidinyl)-phosphine imide in the gas phase and acetonitrile - a DFT study. Tetrahedron Lett. 2006, 47, 2553-2555. (19) Barić, D.; Kovačević, B. Designing a next generation of proton sponges: cyclopropeniminophosphazenes as the strongest pincer ligands. Tetrahedron Lett. 2016, 57, 442-445.

(20) Alder, R. W.; Bowman, P. S.; Steele, W. R. S.; Winterman, D. R. The remarkable basicity of 1,8-bis(dimethylamino)naphthalene. Chem. Commun. 1968, 723-724.

(21) (a) Raab, V.; Gauchenova, E.; Merkoulov, A.; Harms, K.; Sundermeyer, J.; Kovačević, B.; Maksić, Z. B. 1,8-Bis(hexamethyltriaminophosphazenyl)naphthalene, HMPN: a superbasic bisphosphazene "proton sponge". J. Am. Chem. Soc. 2005, 127, 15738-15743. (b) Kögel, J. F.; Oelkers, B.; Kovačević, B.; Sundermeyer, J. A new synthetic pathway to the second and third generation of superbasic bisphosphazene proton sponges: the run for the best chelating ligand for a proton. J. Am. Chem. Soc. 2013, 135, 17768-17774.

(22) (a) Howard, S. T.; Platts, J. A.; Alder, R. W. Ab Initio Studies of Proton Sponges. 2: 1,6-Diazabicyclo[4.4.4]tetradecane. J. Org. Chem. 1995, 60, 6085-6090. (b) Howard, S. T.; Platts, J. A. Ab initio studies of proton sponges. 4: calculating the strain energy. J. Org. Chem. 1998, 63, 3568-3571. (c) Llamas-Saiz, A. L.; Foces-Foces, C.; Elguero, J. Proton sponges. J. Mol. Struct. 1994, 328, 297-323.

(23) (a) Pozharskii, A. F.; Ozeryanskii, V. A. Proton sponges. In The Chemistry of Anilines; Rappoport, Z., Ed.; John Wiley \& Sons: Chichester, 2007; Part 2, Chapter 17, pp 931-1019. (b) Pozharskii, A. F.; Degtyarev, A. V.; Ryabtsova, O. V.; Ozeryanskii, V. A.; Kletskii, M. E.; Starikova, Z. A.; Sobczyk, L.; Filarowski, A. 2- $\alpha$-Hydroxyalkyland 2,7-Di( $\alpha$ - hydroxyalkyl)-1,8-bis(dimethylamino)naphthalenes: Stabilization of Non-Conventional In/Out-Conformers of "Proton Sponges" via N...H-O Intramolecular Hydrogen Bonding. A Remarkable Kind of Tandem Nitrogen Inversion. J. Org. Chem. 2007, 72, 3006-3019. (c) Kostyanowskii, R. G.; Pozharskii, A. F.; Kadorkina, G. K.; Nabiev, O. G.; Degtyarev, A. V.; Malyshev, O. R. Spontaneous resolution of a chiral proton sponge. Mendeleev Commun. 2007, 17, 214-219.

(24) (a) Klisch, M.; Richter, P.; Puchta, R.; Häder, D.-P.; Bauer, W. The Stereostructure of Porphyra-334: An Experimental and Calculational NMR Investigation. Evidence for an Efficient Proton Sponge. Helv. Chim. Acta 2007, 90, 488-511. (b) Kostić, M. D.; Divac, V. M.; Alzoubi, B. M.; Puchta, R. Aplicyanins - brominated natural marine products with superbasic character. Z. Naturforschung B 2016, 71, 883-889.

(25) Bruns, H.; Patil, M.; Carreras, J.; Vázquez, A.; Thiel, W.; Goddard, R.; Alcarazo, M. Synthesis and coordination properties of nitrogen(I)-based ligands. Angew. Chem. Int. Ed. 2010, 49, 36803683.

(26) (a) Belding, L.; Dudding, T. Synthesis and theoretical investigation of a 1,8 -bis(bis(diisopropylamino)cyclopropeniminyl)naphthalene proton sponge derivative. Chem.-Eur J. 2014, 20, 1032-1037. (b) Belding, L.; Stoyanov, P.; Dudding, T. Synthesis, theoretical Analysis, and experimental $\mathrm{p} K_{\mathrm{a}}$ determination of a fluorescent, nonsymmetric, in-out proton sponge. J. Org. Chem. 2016, 81, 6-13.

(27) Breslow, R. Synthesis of the $s$-triphenylcyclopropenyl cation. J. Am. Chem. Soc. 1957, 79, 5318.

(28) (a) Nozoe, T.; Seto, S.; Matsumura, S.; Terasawa, T. The Synthesis of 1-azaazulene and its Derivatives. Chem. Ind. 1954, 13571358. (b) Nozoe, T.; Kitahara, Y.; Arai, T. Synthesis of 3-Phenyl-1azazulene. Proc. Jpn. Acad. 1954, 30, 478-481. (c) Nozoe, T.; Seto, S.; Nozoe, S. Syntheses of azulene and 1-azaazulanone derivatives by the application of cyanoacetamide to tropolone and 4-methyltropolone methyl ethers. Proc. Jpn. Acad. 1956, 32, 472-475.

(29) (a) Nitta, M.; Lino, Y.; Hara, E.; Kobayashi, T. On the reaction of $\mathrm{N}$-vinyliminophosphoranes. Part 7. A short new 1-aza-azulene synthesis. J. Chem. Soc. Perkin Trans. 1 1989, 51-56. (b) Takayasu, T.; Nitta, M. An enamine method for the synthesis of 1-azaazulene derivatives. Reactions of troponimines with enamines. J. Chem. Soc. Perkin Trans. 1 1999, 687-692. (c) Nitta, M. Reviews on Heteroatom Chemistry; Ohno, A., Okuyama, T., Eds.; MYU: Tokyo, 1993; Vol. 9, pp 87-121.

(30) (a) Chiba, S.; Kitamura, M.; Saku, O.; Narasaka, K. Synthesis of 1 -azaazulenes from cycloheptatrienylmethyl ketone $O$-pentafluorobenzoyloximes by palladium-catalyzed cyclization and oxidation. Bull. Chem. Soc. Jpn. 2004, 77, 785-796. (b) Kitamura, M.; Chiba, S.; Saku, O.; Narasaka, K. Palladium-catalyzed synthesis of 1-azaazulenes from cycloheptatrienylmethyl ketone $O$-pentafluorobenzoyl oximes. Chem. Lett. 2002, 31, 606-607.

(31) Carret, S.; Blanc, A.; Coquerel, Y.; Berthod, M.; Greene, A. E.; Deprés, J.-P. Approach to the blues: a highly flexible route to the azulenes. Angew. Chem. Int. Ed. 2005, 44, 5130-5133.

(32) Frisch, M. J.; Trucks, G. W.; Schlegel, H. B.; Scuseria, G. E.; Robb, M. A.; Cheeseman, J. R.; Scalmani, G.; Barone, V.; Mennucci, B.; Petersson, G. A.; Nakatsuji, H.; Caricato, M.; Li, X.; Hratchian, H. P.; Izmaylov, A. F.; Bloino, J.; Zheng, G.; Sonnenberg, J. L.; Hada, M.; Ehara, M.; Toyota, K.; Fukuda, R.; Hasegawa, J.; Ishida, M.; Nakajima, T.; Honda, Y.; Kitao, O.; Nakai, H.; Vreven, T.; Montgomery, J. A., Jr.; Peralta, J. E.; Ogliaro, F.; Bearpark, M.; Heyd, J. J.; Brothers, E.; Kudin, K. N.; Staroverov, V. N.; Kobayashi, 
R.; Normand, J.; Raghavachari, K.; Rendell, A.; Burant, J. C.; Iyengar, S. S.; Tomasi, J.; Cossi, M.; Rega, N.; Millam, J. M.; Klene, M.; Knox, J. E.; Cross, J. B.; Bakken, V.; Adamo, C.; Jaramillo, J.; Gomperts, R.; Stratmann, R. E.; Yazyev, O.; Austin, A. J.; Cammi, R.; Pomelli, C.; Ochterski, J. W.; Martin, R. L.; Morokuma, K.; Zakrzewski, V. G.; Voth, G. A.; Salvador, P.; Dannenberg, J. J.; Dapprich, S.; Daniels, A. D.; Farkas, Ö.; Foresman, J. B.; Ortiz, J. V.; Cioslowski, J.; Fox, D. J. Gaussian09, Revision D.01; Gaussian, Inc.: Wallingford CT, 2009.

(33) Fifen, J. J.; Dhaouadi, Z.; Nsangou, M. Revision of the thermodynamics of the proton in gas phase. J. Phys. Chem. A 2014, 118, 11090-11097.

(34) Glasovac, Z.; Eckert-Maksić, M.; Maksić, Z. B. Basicity of organic bases and superbases in acetonitrile by the polarized continuum model and DFT calculations. New J. Chem. 2009, 33, 588-597.

(35) (a) Barone, V.; Cossi, M. Quantum calculation of molecular energies and energy gradients in solution by a conductor solvent model. J. Phys. Chem. A 1998, 102, 1995-2001. (b) Cossi, M.; Rega, N.; Scalmani, G.; Barone, V. Energies, structures, and electronic properties of molecules in solution with the C-PCM solvation model. J. Comp. Chem. 2003, 24, 669-681.

(36) Lõkov, M.; Tshepelevitsh, S.; Heering, A.; Plieger, P. G.; Vianello, R.; Leito, I. On the basicity of conjugated nitrogen heterocycles in different media. Eur. J. Org. Chem. 2017, 4475-4489.

(37) (a) Raczyńska, E. D.; Gal, J.-F.; Maria, P.-C. Gas-phase basicity of aromatic azines: A short review on structural effects. Int. J. Mass Spectrom. 2017, 418, 130-139. (b) Raczyńska, E. D.; Decouzon, M.; Gal, J.-F.; Maria, P.-C.; Taft, R. W.; Anvia, F. Gas-phase basicity of polyfunctional amidinazines: Experimental evidence of preferred site(s) of protonation. J. Org. Chem. 2000, 65, 4635-4640. (c) Despotović, I.; Vianello, R. Engineering exceptionally strong oxygen superbases with 1,8-diazanaphthalene di-N-oxides. Chem. Commun. 2014, 50, 10941-10944.

(38) Maksíc, Z. B.; Kovačević, B. Absolute proton affinity of some polyguanides. J. Org. Chem. 2000, 65, 3303-3309.

(39) (a) Hirshfeld, F. L. Bonded-atom fragments for describing molecular charge densities. Theor. Chem. Acc. 1977, 44, 129-138.

(b) Ritchie, J. P. Electron density distribution analysis for nitromethane, nitromethide, and nitramide. J. Am. Chem. Soc. 1985, 107, 1829-1837. (c) Ritchie, J. P.; Bachrach, S. M. Some methods and applications of electron density distribution analysis. J. Comp. Chem. 1987, 8, 499-509.

(40) Bader, R. F. W. Atoms in Molecules: A Quantum Theory; Oxford University Press, 1990.

(41) Keith, T. A. AIMAll, version 11.08.23; TK Gristmill Software: Overland Park, KS, USA, 2011.

(42) Afonin, A. V.; Vashchenko, A. V.; Sigalov, M. V. Estimating the energy of intramolecular hydrogen bonds from $1 \mathrm{H}$ NMR and QTAIM calculations. Org. Biomol. Chem. 2016, 14, 11199-11211.

(43) Espinosa, E.; Molins, E.; Lecomte, C. Hydrogen bond strengths revealed by topological analyses of experimentally observed electron densities. Chem. Phys. Lett. 1998, 285, 170-173.

(44) Schleyer, P. v. R.; Maerker, C.; Dransfeld, A.; Jiao, H.; van Eikema Hommes, N. J. R. Nucleus-independent chemical shifts: a simple and efficient aromaticity probe. J. Am. Chem. Soc. 1996, 118, 6317-6318.

(45) Leito, I.; Koppel, I. A.; Koppel, I.; Kaupmees, K.; Tshepelevitsh, S.; Saame, J. Basicity Limits of Neutral Organic Superbases. Angew. Chem. Int. Ed. 2015, 54, 9262-9265. 